Artigo original

Hegemonia - Revista Eletrônica de Relações Internacionais do Centro Universitário Unieuro

ISSN: 1809-1261

UNIEURO, Brasília, número 7, 2011, pp. 147-172.

Recebido em: 14/9/2010

Revisado em: 23/10/2010

Aprovado em: 27/11/2010

\title{
Organização Mundial do Comércio e o Sistema de Solução de Controvérsias
}

Costa, Tiffani Guimarães ${ }^{1}$

Resumo: Devido à complexidade dos fluxos comerciais e à concorrência entre os grandes agentes econômicos no mundo global, percebe-se o interesse generalizado em relação e às formas propostas no âmbito da Organização Mundial do Comércio para solucioná-las. A Organização Mundial do Comércio foi criada para promover e arbitrar as relações comerciais internacionais. Este trabalho tem como objetivo discutir o Sistema de Solução de Controvérsias no âmbito da OMC, proposto como um mecanismo para a resolução e pacificação de temas controversos e conflitos no âmbito das relações internacionais.

Palavras-chave: Sistema de Solução de Controvérsias, conflito e negociação.

Abstract: Due to the complexity of trade and competition among major economic actors in the global world, we see the widespread interest in relation to the forms and proposals within the World Trade Organization to resolve them. The World Trade Organization was established to promote and arbitrate international trade relations. This paper aims to discuss the Dispute Settlement System of the WTO, proposed as a mechanism for resolving controversial issues and peace and conflict in international relations.

Key-words: System of Dispute Resolution, conflict and negotiation.

1 Bacharel em Relações Internacionais. 
Artigo original

Hegemonia - Revista Eletrônica de Relações Internacionais do Centro Universitário Unieuro

ISSN: 1809-1261

UNIEURO, Brasília, número 7, 2011, pp. 147-172.

\section{Introdução}

A Organização Mundial do Comércio foi criada em 1995, como uma instituição intergovernamental global multilateral, com o objetivo de promover e arbitrar às relações comerciais internacionais.

Devido à complexidade dos fluxos comerciais e à concorrência entre os grandes agentes econômicos no mundo global, percebe-se o interesse generalizado em relação às controvérsias e às formas propostas no âmbito da Organização Mundial do Comércio para solucioná-las.

Esse trabalho tem como objeto o Sistema de Solução de Controvérsias no contexto da Organização Mundial do Comércio, pensado a partir dos conflitos e consensos que ele possibilita, com base na análise de alguns casos em que esse mecanismo teve de ser acionado.

O objetivo central do trabalho é refletir sobre o Sistema de Solução de Controvérsias abrangendo o seu funcionamento, sua estrutura e eficácia. Como objetivos específicos o trabalho pretende; conhecer o processo de formação da Organização Mundial do Comércio e do Sistema de Solução de Controvérsias; investigar de que maneira as relações de poder atravessam a organização, definindo os seus rumos; examinar os mecanismos propostos para a condução dos impasses e alcance de consensos. 
Artigo original

Hegemonia - Revista Eletrônica de Relações Internacionais do Centro Universitário Unieuro

ISSN: 1809-1261

UNIEURO, Brasília, número 7, 2011, pp. 147-172.

O problema central do estudo refere-se à questão da negociação no âmbito da Organização Mundial do Comércio, pensada a partir de um sistema criado para encaminhá-la. Assim, as questões propostas são: Como definir o processo de negociação nas relações internacionais?; de que maneira as relações de poder entre os Estados influenciam nesse processo? e, o que é o Sistema de Solução de Controvérsias e qual a sua eficácia nesse cenário?

O estudo tem como objeto a negociação nas relações internacionais e o sistema de solução de controvérsias. Nesse sentido, as contribuições de Costa Vaz (2002) sobre o processo de negociação nas relações internacionais são fundamentais. Quanto à análise do sistema de solução de controvérsias, utilizamos as contribuições de Brigadão (2006); Lafer (1998); Thorstensen (2001); Amaral (2008); e Hoffmann (2004).

Esse trabalho é importante pelo fato do tema se referir a questões de muita importância para o entendimento do desenrolar das negociações do Comércio Internacional. Assim, pretende contribuir para uma melhor compreensão, no âmbito da Organização Mundial do Comércio, o sistema de solução de controvérsias, buscando compreender as negociações que se operam nesse contexto. Trata-se de uma questão de relevante interesse para o conhecimento das relações internacionais, no campo do comércio internacional. 
Artigo original

Hegemonia - Revista Eletrônica de Relações Internacionais do Centro Universitário Unieuro

ISSN: 1809-1261

UNIEURO, Brasília, número 7, 2011, pp. 147-172.

O artigo está organizado da seguinte forma. Primeiro, apresentamos e contextualizamos a Organização Mundial do Comércio no sistema internacional. Na seqüência, analisamos o processo de negociação nas relações internacionais, para chegarmos ao Sistema de Solução de Controvérsias. Por fim, concluímos respondendo à principal questão do trabalho: De que maneira as relações de poder entre os Estados influenciam nesse processo?

\section{A Organização Mundial do Comércio (World Trade Organization)}

O desenvolvimento do comércio internacional vem acompanhando diretamente o sistema internacional, já que as relações comerciais são uma das principais áreas estabelecidas no sistema internacional, mesmo antes da formação dos Estados soberanos. Apesar da grande quantidade de acordos que foram sendo concluídos ao longo dos séculos, é somente após a Segunda Guerra Mundial que podemos ver um regime comercial de abrangência internacional.

Com o fim da Segunda Guerra Mundial, os países decidiram regular as suas relações econômicas internacionais, não só com o objetivo de proporcionar melhores condições de vida para os seus cidadãos, como 
Artigo original

Hegemonia - Revista Eletrônica de Relações Internacionais do Centro Universitário Unieuro

ISSN: 1809-1261

UNIEURO, Brasília, número 7, 2011, pp. 147-172.

também por terem percebido que essa questão era crucial a manutenção da paz nas relações entre os Estados.

Os Estados tinham, nesse contexto, o objetivo de criarem uma ordem econômica internacional. Em 1944, foi concluído um acordo, em Bretton Woods, nos EUA, tendo como objetivo criar um ambiente de cooperação na área econômica, baseado no estabelecimento de três instituições internacionais: FMI (Fundo Monetário Internacional), tendo a função de manter a estabilidade de taxas de câmbio e assistir os países com problemas de balanço de pagamentos através de acesso a fundos especiais; BIRD (Banco Internacional para Reconstrução e Desenvolvimento), tendo como função fornecer os capitais necessários para reconstrução dos países atingidos pela guerra; e a OIC (Organização Internacional do Comércio), tendo como função coordenar e supervisionar a negociação de um novo regime para o comércio mundial.

O FMI e o BIRD foram efetivados. Para Boaventura, "Tanto o Bird como o FMl foram criados sob a égide do pensamento de Keynes, na crença de que os mercados funcionam freqüentemente mal e que as suas falhas devem ser compensadas por uma forte intervenção do Estado na economia (política fiscal, investimento público etc.)".(2005, 1)

A Organização Internacional do Comércio, diferente dos dois organismos, não foi estabelecida, pois nunca chegou a ser ratificada por um 
Artigo original

Hegemonia - Revista Eletrônica de Relações Internacionais do Centro Universitário Unieuro

ISSN: 1809-1261

UNIEURO, Brasília, número 7, 2011, pp. 147-172.

de seus principais membros, os Estados Unidos. A Carta de Havana, de 1947, que delimitava os objetivos e funções, na verdade, não foi submetida ao Congresso dos Estados Unidos. A maioria dos deputados, na época, temiam que a nova instituição iria restringir excessivamente a soberania dos Estados Unidos na área do comércio internacional.

Então, ainda em 1947, 23 países se reuniram e foi negociado um Acordo Provisório, que passou a ser chamado de GATT (Acordo Geral sobre Tarifas e Comércio), que adotava apenas um segmento da Carta de Havana, relativo às negociações de tarifas e regras de comércio. Este acordo tinha como principal objetivo regular provisoriamente as relações internacionais comerciais, pois na época os países adotaram uma série de medidas para proteger os produtos nacionais e evitar a entrada de produtos de outros países, por meio de altos impostos para importação. Na ausência de uma real organização internacional para o comércio, o GATT supriu essa demanda. Como afirma Clóvis Brigadão:

“O GATT gerou a expectativa de que as relações das nações signatárias nos domínios comercial e econômico fossem orientadas no sentido de elevar os padrões de vida, de assegurar o emprego pleno e um alto e crescente nível de rendimento real e efetivo, para ampla exploração dos recursos mundiais. Além disso, esperava-se do mesmo a expansão da produção e das trocas de 
Artigo original

Hegemonia - Revista Eletrônica de Relações Internacionais do Centro Universitário Unieuro

ISSN: 1809-1261

UNIEURO, Brasília, número 7, 2011, pp. 147-172.

mercadorias, principalmente através da conclusão de acordos recíprocos e mutuamente vantajosos que visavam à redução substancial de tarifas aduaneiras e de outras barreiras." $(2006,36)$

O GATT, além de um foro de negociações, também era árbitro das regras entre as partes. Com o passar dos anos, foi sendo atualizado e teve seu escopo de incidência ampliado, através de alterações efetuadas como resultado de negociações levadas a efeito nas chamadas "rodadas", que visavam quase sempre à liberalização progressiva do comércio internacional dentro de certos princípios.

Foram oito rodadas de negociações realizadas pelo GATT. A primeira rodada, Rodada Genebra, em 1947, concentrou-se na redução das tarifas de comércio, assim como a Rodada Annecy (1949), a Rodada Torquay (1951), a Rodada Genebra (1956) e a Rodada Dillon (1960-1961). A sexta rodada, Rodada Kennedy (1964-1967), teve como questões temáticas negociadas, o Acordo Antidumping e discussões sobre o desenvolvimento. A primeira tentativa de acabar com as barreiras nãotarifárias aconteceu na sétima rodada, conhecida como Rodada Tóquio (1973-1979).

Durante a Guerra Fria, o GATT englobava praticamente todos os países capitalistas. Com a dissolução do bloco soviético, a maioria dos países 
Artigo original

Hegemonia - Revista Eletrônica de Relações Internacionais do Centro Universitário Unieuro

ISSN: 1809-1261

UNIEURO, Brasília, número 7, 2011, pp. 147-172.

ex- comunistas também aderiram ao Acordo. Com o fim da Guerra Fria, os países assumiram a forte tendência de se organizarem em blocos comerciais, pois a eliminação do panorama bipolar das relações internacionais permitiu o aparecimento do multilateralismo, prática que envolve o estabelecimento de princípios que norteiam as relações entre os atores, no contexto da globalização. Diante dessas circunstâncias, as fronteiras do capitalismo alargaram-se fazendo com que os países percebessem que a capacidade do GATT estava se esgotando para atuar como instrumento adequado na administração do comércio mundial.

Os Estados, diante de novos desafios, resolveram se unir para mais uma rodada de negociações. A oitava rodada, a Rodada Uruguai foi a mais ambiciosa e complexa das negociações estabelecidas no âmbito do GATT. Foi iniciada em 1986, na cidade de Punta Del Este e foi finalizada, no dia 15 de abril de 1994, com a criação da OMC (Organização Mundial do Comércio). Segundo Rego, "foi na Rodada do Uruguai que o GATT conseguiu o maior número de conquistas. Tais negociações talvez possam ser consideradas as mais amplas sobre questões econômicas já realizadas até hoje, cobrindo uma extensa gama de assuntos, alguns deles extremamente sensíveis." $(1996,6)$

O termo GATT ficou estabelecido para designar o conjunto de todas as regras sobre o comércio negociadas desde 1947, também como 
Artigo original

Hegemonia - Revista Eletrônica de Relações Internacionais do Centro Universitário Unieuro

ISSN: 1809-1261

UNIEURO, Brasília, número 7, 2011, pp. 147-172.

para incorporar as modificações introduzidas pelas sucessivas rodadas de negociações até a Rodada do Uruguai. Assim, o GATT morreu como órgão internacional, mas está vivo como sistema das regras do comércio internacional da OMC.

Para Michael Hart, os membros do GATT decidiram, "abandonar o conservadorismo e tentar novamente desenvolver um código mais abrangente de políticas comerciais que tivesse apelo universal." (1998: 27)

Os resultados da Rodada Uruguai passaram a determinar as regras do comércio internacional, não só dos grandes parceiros internacionais para diminuir os conflitos entre eles, mas também dos pequenos e médios parceiros que passam a ter na OMC a organização de supervisão e de apoio para assegurar o acesso aos mercados protegidos dos próprios países mais desenvolvidos, bem como dos grandes acordos regionais de comércio.

A Rodada Uruguai, sob a ótica das afirmações de Celso Lafer, representa a busca de denominador comum, cujo limite foi o próprio consenso:

“Há um potencial de sociabilidade e solidariedade na esfera internacional. Este potencial provê - e este é o pressuposto no qual se fundamenta a OMC - uma interação organizada e não anárquica 
Artigo original

Hegemonia - Revista Eletrônica de Relações Internacionais do Centro Universitário Unieuro

ISSN: 1809-1261

UNIEURO, Brasília, número 7, 2011, pp. 147-172.

entre os atores da vida econômica num mercado globalizado, que não funciona como um jogo de soma zero, em que o ganho de um significa a perda do outro. Há conflito, mas há também cooperação, lastreada num processo abrangente que tem sua base na racionalidade e na funcionalidade da reciprocidade de interesses. Somente se pode perceber e julgar adequadamente essa reciprocidade de interesses se estão visivelmente à tona, através da publicidade contemplada pelo princípio de transparência." $(1998,28)$

A OMC firmou-se como uma organização internacional de caráter permanente com países-membros, abrangendo também os serviços e a propriedade intelectual. É uma instituição com personalidade jurídica que surgiu com o objetivo de proporcionar e regulamentar o livre comércio entre as nações participantes.

A OMC foi a primeira organização internacional do mundo pósguerra fria. Ela reúne a maior parte dos Estados, recobrindo matérias muito variadas. Estabeleceu o novo marco regulatório para comércio internacional, procurando disciplinar as interações oriundas da interação dos mercados.

A organização inclui 153 membros e tem sua sede em Genebra, na Suíça. Tem como temas de discussões do seu foro o comércio relacionado ao meio ambiente, investimentos, concorrência, facilitação de comércio, comércio eletrônico e cláusulas sociais. 
Artigo original

Hegemonia - Revista Eletrônica de Relações Internacionais do Centro Universitário Unieuro

ISSN: 1809-1261

UNIEURO, Brasília, número 7, 2011, pp. 147-172.

Para Thorstensen, a OMC em outras palavras é, “A organização que coordena as negociações das regras do comércio internacional e supervisiona a prática de tais regras, além de coordenar as negociações sobre novas regras ou temas relacionados ao comércio." (2003:41)

A OMC desordena um novo universo, que precisa ser mais conhecido pelas conseqüências que gera em todos os campos da atividade econômica das nações e por ser o trampolim de inserção no comércio internacional. Por meio de normas de cooperação mútua a OMC busca a promoção do interesse comum. Celso Lafer argumenta que:

"Em outros organismos internacionais, tais como o Conselho de Segurança das Nações Unidas ou a Conferência do Desarmamento, que tratam de temas de segurança e cujo limite é a paz ou a guerra, o recuso obstrucionista ao veto é considerado legítimo e ocorre com freqüência porque, teoricamente, a sobrevivência do Estado como uma unidade independente pode estar em jogo. A OMC, como uma expressão de direito internacional de cooperação no campo econômico e um foro de negociação de interesse geral, não opera sob a mesma presunção. Sua premissa é operar dentro, e não fora do sistema. O consenso é a contrapartida dessa premissa na $\mathrm{OMC}$, enquanto um foro negociador de um direito internacional de cooperação. Essa é a razão pela qual as normas da OMC não podem ser impostas por meio de um 'pactum subjectionis'. Todos os membros da OMC criam e estabelecem 
Artigo original

Hegemonia - Revista Eletrônica de Relações Internacionais do Centro Universitário Unieuro

ISSN: 1809-1261

UNIEURO, Brasília, número 7, 2011, pp. 147-172.

regras por meio de um 'pactum societatis', que assegura uma efetiva dimensão de aceitação generalizada." (1998:38)

A Organização Mundial do Comércio é um lócus em relação ao qual confluem todas as vertentes, isto é tem peso e importância tanto quanto a experiência prática que produz, quanto ao conhecimento teórico. É uma organização gera assegurar e defender a especificidade dos distintos interesses gerais, cujo patrimônio é constituído por normas de mútua colaboração que administram uma solução entre o "interno" e o "externo" que atualmente caracteriza o comércio mundial na era da globalização.

A OMC é uma instituição internacional composta estruturalmente pela Conferência Ministerial, órgão máximo, o qual tem a autoridade para tomar as decisões dentro de qualquer um dos Acordos Multilaterias. O Conselho Geral é o corpo diretor. Já o Órgão de Revisão de Política Comercial foi criado como mecanismo para examinar as políticas de cada membro da OMC. O Conselho para Bens, Serviços e Propriedade Intelectual foi criado para acompanhar a implementação das regras negociadas em cada uma das áreas. Existem também órgãos de supervisão específicos, denominados, comitês, subordinados aos conselhos, como o Comitê de Comércio de Desenvolvimento, o Comitê de Restrições por Balanço de Pagamentos, Comitê de Assuntos Orçamentários, Financeiros e 
Artigo original

Hegemonia - Revista Eletrônica de Relações Internacionais do Centro Universitário Unieuro

ISSN: 1809-1261

UNIEURO, Brasília, número 7, 2011, pp. 147-172.

Administrativo. O Secretariado tem responsabilidade de caráter internacional, não devendo pedir, nem receber instruções de qualquer governo ou outra autoridade externa à OMC. Por fim, o Órgão de Solução de Controvérsias, criado como mecanismo de solução de conflitos na área do comércio, é de grande importância e é de natureza quase judicial.

\section{O processo de negociação nas Relações I nternacionais}

Cabe lembrar que todas as instituições e mecanismos criados, do GATT à OMC, tiveram como objetivo a resolução e a pacificação de temas controversos e conflitos no âmbito das relações internacionais. Isto é, no sentido de viabilizar o mecanismo de negociação, algo fundamental nas relações internacionais.

No que se refere à prática da negociação nas relações internacionais, muito já foi discutido. Para Costa Vaz:

“A negociação internacional não deve ser entendida como um processo cuja dinâmica e resultados sejam determinados fundamentalmente pelas características subjetivas, pelo talento, pela habilidade e pela sabedoria dos negociadores no emprego de diferentes recursos com o propósito de produzir um resultado 
Artigo original

Hegemonia - Revista Eletrônica de Relações Internacionais do Centro Universitário Unieuro

ISSN: 1809-1261

UNIEURO, Brasília, número 7, 2011, pp. 147-172.

desejado ou tido como satisfatório, envolvendo a barganha, a persuasão ou mesmo a chantagem." (2002: 41)

No entanto, visto pelo prisma da análise estrutural, Costa Vaz afirma, com base em Dupont que, "Na análise estrutural, assume-se que toda negociação, inclusive a internacional, a despeito das diferenças entre esta e outras formas, envolve elementos cuja interação conforma um campo de forças e que definem sua essência e dinâmica." (2002: 42)

Ainda segundo Costa Vaz, a negociação pressupõe um sistema constituído por diversos elementos, tais como: atores, estrutura, estratégicas, processos e resultados. Sua natureza resulta da individualidade de elementos cooperativos e conflitivos, o que leva pensa - lá a partir de dois conceitos: o de negociação integrativa e o de negociação distributiva. De acordo com o autor, a negociação integrativa é,

“Fundamentalmente uma negociação de projetos em que sobressaem a valorização da criatividade, a busca de opções construtivas e dinâmicas e a mobilização de idéias e de ações novas, correspondendo ao que se denomina, na teoria dos jogos, um jogo de soma positiva, no qual o desfecho alcançado implica ganhos relativos para todas as partes envolvidas." (2002: 52). 
Artigo original

Hegemonia - Revista Eletrônica de Relações Internacionais do Centro Universitário Unieuro

ISSN: 1809-1261

UNIEURO, Brasília, número 7, 2011, pp. 147-172.

Já a negociação distributiva, ainda conforme C. Vaz,

"Associa-se a um jogo de soma-zero, onde duas partes, agindo individualmente ou liderando coalizões com interesses opostos em relação a um tema procuram afirmar sua posição perante a da outra parte, destacando-se o sentido de competição e o caráter eminente conflitivo dos interesse em jogo. Nesse tipo de negociação, os resultados refletem, necessariamente a prepoderância de uma parte em detrimento dos interesses e das posições da outra." (2002:52)

Conclui-se assim que a negociação integrativa envolve um processo em que ocorrem tanto concessões, como busca de alternativas para o problema em questão na negociação. Já a negociação distributiva consiste diretamente na realização de concessões. Assim, a partir desses conceitos, podemos melhor analisar o Sistema de Solução de Controvérsias, na medida em que ele pressupõe mecanismos de negociação permanentemente acionados.

\section{O Sistema de Solução de Controvérsias da OMC}


Artigo original

Hegemonia - Revista Eletrônica de Relações Internacionais do Centro Universitário Unieuro

ISSN: 1809-1261

UNIEURO, Brasília, número 7, 2011, pp. 147-172.

O Sistema de Solução de Controvérsias já existe desde a criação do GATT. No início da criação do GATT, a energia do sistema era proveniente dos elementos políticos dos procedimentos. Os painéis esperavam a conciliação de posições conflitantes e não a adjudicação de um caso.

O sistema necessitava de um consenso das partes na disputa para todos os passos no procedimento: o estabelecimento do painel; a determinação de seu mandato; a decisão de sua composição e, a adoção do laudo arbitral. Com isso, os procedimentos só poderiam ser usados com eficácia nos casos que ambas as partes estivessem dispostas a aceitar a solução arbitrada.

O sistema do GATT, em casos de conflitos comerciais, previa um processo de consulta e depois a organização de painéis que elaboravam um relatório sobre a controvérsia. E esse relatório devia ser aprovado, por consenso, pelo Conselho Geral. Ou seja, bastava a parte perdedora não aceitar o relatório para que todo o processo fosse bloqueado.

Quando foi alcançada a Rodada Uruguai, o sistema se encontrava totalmente desmoralizado. As falhas sistêmicas eram sobre a possibilidade de bloqueio do painel de arbitragem e na falta de se poder executar laudos arbitrais. O que causava a desmoralização era saber que o 
Artigo original

Hegemonia - Revista Eletrônica de Relações Internacionais do Centro Universitário Unieuro

ISSN: 1809-1261

UNIEURO, Brasília, número 7, 2011, pp. 147-172.

sistema permitia que as partes contratantes pudessem ignorá-lo. Ou seja, durante a Rodada Uruguai procurou-se aperfeiçoar o sistema.

Um dos principais resultados da Rodada Uruguai foi o Tratado “Entendimento sobre Regras e Procedimentos Governando a Resolução de Disputas", que incorporou alterações no Sistema de Solução de Controvérsias do GATT de 1947.

O novo mecanismo de Solução de Controvérsias da OMC, constituído por este tratado, representou o pilar central do sistema multilateral comercial. Segundo Lafer:

“O Sistema de Solução de Controvérsias da OMC, é a de que, enquanto expressão de codificação e desenvolvimento progressivo e em contraste com o sistema do GATT, não é mero fruto de prática e interpretação. É uma obrigação de outra hierarquia jurídica, posto que contemplada pelo próprio Tratado constitutivo da OMC e enquanto tal, obriga a todos os estados-membros e deve ser cumprida de boa fé. Em outras palavras, é parte do quadro constitutivo de uma nova organização - ela própria dotada de subjetividade internacional especializada, distinta de seus membros - o que não acontecia com o GATT - que era de natureza contratual." (1998: 121) 
Artigo original

Hegemonia - Revista Eletrônica de Relações Internacionais do Centro Universitário Unieuro

ISSN: 1809-1261

UNIEURO, Brasília, número 7, 2011, pp. 147-172.

Com a criação da OMC, reformou-se o Sistema de Solução de Controvérsias de tal forma que os problemas passados foram corrigidos e sua eficácia foi aumentada, tornando-o um mecanismo mais complexo e elaborado. As regras eram mais claras e precisas, se aproximando de um sistema jurisdicional.

O Sistema de Solução de Controvérsias da OMC exerce um controle sobre todos os membros, garantindo o cumprimento efetivo das obrigações e regras que constituem a ordem jurídica da organização. Busca também, preservar os direitos e as vantagens obtidas pelos membros, no âmbito do sistema multilateral de comércio. O sistema também possui a função de evitar que os membros atuem de forma unilateral, impondo medidas que os punissem contra os demais, sempre que estes acreditassem que seus interesses, protegidos pelo sistema normativo da OMC, estivessem ameaçados.

Conforme previsto na Carta da Organização Mundial do Comércio, pode o Sistema de Solução de Controvérsias estabelecer punições e sanções ou multas aos países que não respeitarem seus princípios. Ademais, não é permitido que sejam feitas reservas em relação a qualquer disposição do acordo, como mostra o Parágrafo 4o do Título Outras Disposições, “Todo membro deverá assegurar a conformidade de suas leis, 
Artigo original

Hegemonia - Revista Eletrônica de Relações Internacionais do Centro Universitário Unieuro

ISSN: 1809-1261

UNIEURO, Brasília, número 7, 2011, pp. 147-172.

regulamentos e procedimentos administrativos com as obrigações constantes dos Acordos Anexos."

Um exemplo que podemos citar é o primeiro julgamento do Órgão, no caso, movido por Brasil e Venezuela, quando o Estados Unidos foi condenado pelo sistema e, assim, alteraram norma interna que impunha requisitos mais rígidos de qualidade para a gasolina importada, em comparação com as exigências feitas pela gasolina local.

Nesse caso, do Brasil e da Venezuela contra o Estados Unidos, como foi visto nas contribuições feitas por Costa Vaz, podemos dizer que houve uma negociação distributiva. No caso apresentado houve diretamente a realização de uma concessão, diferente de uma negociação integrativa que busca alternativas "mais leves" para solucionar a questão.

Para Thorstensen, "O novo sistema é mais forte, porque 0 relatório do painel passa a ser obrigatório exigindo que o novo Órgão de Solução de Controvérsias derrube a decisão por consenso, o que é muito mais difícil de ser seguido. É o chamado consenso negativo, que garante a automaticidade das decisões do Órgão." (2003: 371). Para confirmar Thorstesen, vale apresentar as considerações de Prado:

“O mecanismo de Solução de Controvérsias confere à Organização Mundial do Comércio um poder singular no cenário internacional: 
Artigo original

Hegemonia - Revista Eletrônica de Relações Internacionais do Centro Universitário Unieuro

ISSN: 1809-1261

UNIEURO, Brasília, número 7, 2011, pp. 147-172.

no caso de descumprimento de suas decisões, o Órgão de Solução de Controvérsias pode autorizar um membro prejudicado a adotar retaliações comerciais contra o parceiro inadimplente em suas obrigações perante a OMC." (2002: 263)

O Acordo estabeleceu também, como novidade, um Órgão de Apelação, que funciona no sistema como um tribunal de apelação. O Órgão de Apelação tem como função verificar os fundamentos legais do relatório do painel e das suas conclusões. Como afirma Thorstensen:

"A meta de todo o processo, é de reforçar a adoção de práticas compatíveis com os acordos negociados e não punir pela adoção de práticas consideradas incompatíveis com as regras. Na verdade, a prioridade é a de solucionar casos de controvérsias entre os membros, primeiro através de consultas, e somente se um acordo não for possível é que se parte para o painel." (2002: 372)

A operação do Sistema de Solução de Controvérsias da OMC envolve as partes e os terceiros do caso; o Painel do Órgão de Solução de Controvérsias, o Corpo de Apelação e o Secretariado da OMC, além de especialistas independentes. O Órgão de Solução de Controvérsias deriva do Conselho Geral da OMC. Esse órgão é responsável por estabelecer Painéis, adotar os relatórios do mesmo e também pelo Corpo de Apelação. Por fim, 
Artigo original

Hegemonia - Revista Eletrônica de Relações Internacionais do Centro Universitário Unieuro

ISSN: 1809-1261

UNIEURO, Brasília, número 7, 2011, pp. 147-172.

autoriza a suspensão de obrigações de acordo com os acordos já celebrados.

O procedimento do Sistema de Solução de Controvérsias é basicamente dividido em: consultas, painéis, apelação e implementação.

Segundo Prado (2002), a eficácia do mecanismo previsto no Entendimento sobre Solução de Controvérsias da OMC se baseia em três características básicas: abrangência, automaticidade e exeqüibilidade.

Tais características são conceituadas pelo autor como: Abrangência; todos os acordos da OMC estão cobertos pelo mecanismo. A automaticidade deriva da regra do consenso negativo válida para os diversos procedimentos e garante que o mecanismo somente pode ser interrompido por acordo das partes em litígio. Já na exeqüibilidade, verifica-se o descumprimento de decisão do Órgão de Solução de Controvérsias, embasada em relatório do Painel ou do Corpo de Apelação, que prevê quando membro possa solicitar autorização para retaliar.

Podemos então concluir que é nesse Sistema de Solução de Controvérsias que reside a fonte de poder e de influência da Organização Mundial de Comércio. É esse poder que, muitas vezes, leva os países a retirarem ou desistirem de medidas governamentais que causem prejuízos a seus parceiros, sejam eles potências ou pequenas nações. 
Artigo original

Hegemonia - Revista Eletrônica de Relações Internacionais do Centro Universitário Unieuro

ISSN: 1809-1261

UNIEURO, Brasília, número 7, 2011, pp. 147-172.

\section{Considerações Finais}

Este artigo procurou analisar a questão do Sistema de Solução de Controvérsias no campo das relações comerciais internacionais, particularmente na Organização Mundial do Comércio.

Vimos que o Sistema de Solução de Controvérsias representa um mecanismo fundamental no processo de negociação. Entretanto, conflitos surgem em virtude, por exemplo, nas relações de poder que estabelecem entre os Estados, as quais interferem não só no campo das negociações comerciais, mas nas diversas dimensões.

De que maneira isso ocorre? Segundo Fernando Viera Machado,

"Dentro de uma abordagem institucionalista liberal, a cooperação praticada entre governos ocorre em decorrência de um processo de coordenação política. Ou seja, as políticas formuladas e perseguidas por um governo são consideradas por seus parceiros como facilitados de realização de seus próprios objetivos. O sucesso da cooperação depende do cálculo racional dos atores envolvidos, os quais estabelecem hierarquias de preferências. O estabelecimento dessa hierarquia de preferências é processo de coordenação política que se faz por meio da articulação de custos e benefícios das escolhas que são feitas pelos atores. A escolha 
Artigo original

Hegemonia - Revista Eletrônica de Relações Internacionais do Centro Universitário Unieuro

ISSN: 1809-1261

UNIEURO, Brasília, número 7, 2011, pp. 147-172.

racional, obviamente, se dá no sentido da cooperação e não da discórdia." (ano: 150)

O campo das ciências sociais afirma que a Organização Mundial do Comércio juntamente com o Sistema de Solução de Controvérsias, constituem "processos cooperativos", com o objetivo instaurar solidariedade, lealdades, ordem e equilíbrio nas relações comerciais. Mas como afirma Machado, "sem a percepção de que pode haver conflito, não há necessidade de ocorrer à cooperação. Todavia, pode ocorrer cooperação quando um ator leva em consideração os interesses alheios ao buscar atingir os próprios, mesmo que alguns nada ganhem." (ano: 152)

É dessa forma que os Estados influenciam o processo do Sistema de Solução de Controvérsias. Ainda segundo F. Machado,

“O comportamento de cada ator envolvido na cooperação é motivado por um objetivo, não sendo que este seja igual para todos envolvidos. Por isso é que, no caso da cooperação, os atores adotam um comportamento racional. Além disso, a cooperação permite que os atores obtenham ganhos e recompensas, sem que haja necessidade de que estes sejam, quantitativa e qualitativamente, os mesmos." (ano: 151) 
Artigo original

Hegemonia - Revista Eletrônica de Relações Internacionais do Centro Universitário Unieuro

ISSN: 1809-1261

UNIEURO, Brasília, número 7, 2011, pp. 147-172.

Os Estados, num primeiro momento, têm como as políticas de outros governos como obstáculos para alcance de seus objetivos. No entanto, por meio da Organização Mundial do Comércio e do seu Sistema de Solução de Controvérsias, ou seja, da cooperação e da negociação, ajustes são feitos, levando-se em consideração que as políticas de cada um devem de tornar significativamente mais compatíveis com as de todos os demais.

Escreveu Smith, como mostra o artigo Cooperação o que vem a ser?, de Lima que, "o homem tem oportunidades quase constantes de receber ajuda de seus irmãos e é inútil esperar essa ajuda apenas como benevolência...não é a benevolência do açucareiro, do cervejeiro ou do padeiro que nos proporciona o nosso jantar, e sim a preocupação de cada um deles com seus próprios interesses."(2005: 14)

Dessa forma, podemos então entender que a OMC e o Sistema de Soluções, são instituições nas quais processos e relações cooperativas admitem o conflito de interesses e nas quais muitas vezes os Estados influenciam, sem que percebam, os processos para alcançar os seus objetivos. Como afirma Susan Strange, "a habilidade de um agente ou grupo de agentes de afetar os resultados da interação de tal forma que suas preferências as tenham precedência sobre as preferências dos outros agentes envolvidos." (1996: 17) 
Artigo original

Hegemonia - Revista Eletrônica de Relações Internacionais do Centro Universitário Unieuro

ISSN: 1809-1261

UNIEURO, Brasília, número 7, 2011, pp. 147-172.

Ou seja, apesar de todo o esforço que a OMC junto com o

Sistema de Solução de Controvérsias realizam para serem "justos", os Estados vão sempre buscar os seus interesses, influenciando ou não, através do poder, os resultados das negociações.

\section{Bibliografia}

Livro:

VAZ, Alcides C. Cooperação, integração e processo negociador: A construção do Mercosul. Brasília: Instituto Brasileiro de Relações Internacionais, 2002.

Herz, Mônica, HOFFMANN, Andrea R. Organizações Internacionais: história e práticas. Rio de Janeiro, Elsevier Editora Itda, 2004.

THORSTENSEN, Vera. Organização Mundial do Comércio: As regras do comércio internacional e a nova Rodada de negociações multilaterais. 2.ed. São Paulo, Aduaneira Itda, 2003.

AMARAL, Alberto. OMC e o comércio internacional. São Paulo, Aduaneiras Itda, 2002.

BRIGADÃO, Clóvis. Temas e Dilemas. Rio de Janeiro, Gramma, 2006.

LAFER, Celso. A OMC e a regulamentação do comércio internacional: uma visão brasileira. Porto Alegre, Livraria do Advogado, 1998. 
Artigo original

Hegemonia - Revista Eletrônica de Relações Internacionais do Centro Universitário Unieuro

ISSN: 1809-1261

UNIEURO, Brasília, número 7, 2011, pp. 147-172.

TORRES, Igor Gonçalves. Comércio Internacional no século XXI. São Paulo, Aduaneras, 2000.

MACHADO, Fernando Vieira. Cooperação Técnica entre Países em Desenvolvimento: o Brasil e os países da América Latina. Brasília, UNB, mestrado em Relações Internacionais, 2004.

Artigo em periódico eletrônico:

SANTOS, Boaventura de Souza. A Guerra e a Economia. São Paulo, 7 de abril, 2005. Disponvel em: < www.voltairenet.org/article124551.html > Acesso em 17 de março de 2010.

REGO, Elba Cristina Lima. Do Gatt à OMC: O que mudou, como funciona e para onde caminha o sistema multilateral do comércio. Rio de Janeiro, dezembro de 1996. Disponível em: < http://www.bndes.gov.br/SiteBNDES/export/sites/default/bndes_pt/Galerias /Arquivos/conhecimento/revista/gatt.pdf > Acesso em 17 de março de 2010.

LIMA, Ludmila Moreira. Cooperação, o que vem a ser?. Brasília, 2005. Disponível em: $\quad<\quad$ http://www.unieuro.edu.br/downloads2005/hegemonia_02_02.pdf > Acesso em 11 de abril de 2010. 